https://doi.org/10.22364/hssl.28.1.07

\title{
LEADERSHIP AND CHANGE MANAGEMENT - IN CONTEXT TO CIRCULAR ECONOMY AND RECYCLING INITIATIVES IN THE EUROPEAN PLASTIC INDUSTRY
}

\section{Markus Huemer}

Mg. rer. soc. oec.

\begin{abstract}
Circular Economy is a term which is omnipresent in nowadays discussions about sustainability and climate change. Basically, it shall represent an attitude of resource efficiency, targeting whole non-resource efficient societies and focusing on a sustainable use and reuse of the goods that are produced and used in everyday private and business life. However, Circular Economy is not just a "thing" implementable by promoting the right words, it is an attitude, respectively a way of doing things different than it was done until now, that must be pushed and guided from somehow above, making people and companies follow that approach. Consequently, implementing a sustainable and working Circular Economy requires a trustworthy management of that change, and leaders whom societies, companies or individuals or willing to follow.
\end{abstract}

Keywords: Circular Economy, Change Management, Leadership

\section{Introduction}

Leadership and Change Management as an integral part in companies and industries, consists since the beginning of all business activities. Specific circumstances make changes inevitable; leaders are requested to initiate and direct the change. When the whole planet and environment is asking for a change, the challenge in leadership is at the top level and it requires sustainable and unified actions to realise the change.

Plastic pollution is a very present topic and fills nowadays media. Many people are blaming Plastics itself as the root of all evil, but is this the really the simple truth? Or is it the people, the communities, the states that are to blame because of missing initiatives, missing awareness and missing actions how to prevent from plastic pollution?

A very popular expression in the daily media is the so called "Circular Economy", which shall contain and minimise the negative effects of plastic pollution. Well lead and proper realised, the change from a linear economy to a circular economy is possible, which would not only have ecological benefits, but also economic ones. The goal of this article is to 
investigate appropriate leadership and change management theories, have a look on the European Plastic Industry and then analyse and comment on the leadership and change management actions that have been taken in order to realise the Circular Economy.

Research Object

- Relation of Global Leadership and Change to realising the Circular Economy

Purpose of the research

- Is to link the theories of Global Leadership and Change to the initiatives in Circular Economy.

Problem Position

- Circular Economy is a global topic that requires global actions. All actions that alter the future, in this case to the obviously better one, require partly huge investments companies are often not willing to undertake. As a Circular Economy is key for a sustainable living on our planet, those investments are just inevitable and necessary. Strong leadership decisions will be necessary in order to move from a linear to the Circular Economy

\section{Leadership and Change Management}

When looking at the development in the Recycling Industry, especially the Circular Economy Movement, a deeper insight into the theoretical framework is necessary in order to understand the decisions taken in the past. Naturally, the Circular Economy Movement received highest attention due to the economical and recycling awareness in the last years. However, the subjects that most probably had the biggest influence in going towards a Circular Economy are Leadership and Change Management, as it requires strong leadership, right decisions and people to follow in order to realise the change. Both topics are rather wide and can be applied on many practical business cases. However, it makes sense to analyse Leadership and Change Management from a very theoretical perspective, as the actions and decisions taken have been decided by leaders, in order to survive difficult times and to manage the change that is inevitable in a business environment over decades.

\section{Leadership Theories}

In the literature, many different leadership theories exist. Here in this article the focus will lie on "Great Man Theory", "Contingency Theory" and "Transformational Theory", as those theories are most profound in the article context. Plentiful explanations and classifications exist in 
the modern literature, which mainly emerged in the 20th century. Even through this relatively short period of time, in relation to how long leadership as a science already exists, the various theories have been modified, modernised and re-evaluated quite often. Consequently, one can say, that a theory alone is relatively unconnected and always must be seen in a specific context. This context might be time period or century, modernisation and industrialisation and other environments that influence the necessary style of leadership in the certain area.

The theories chosen and mentioned above are chosen on purpose. For many companies founded years back and still existing, the different leadership theories might reflect the past leadership styles. At the beginning of the foundation, a great man had the vision to create, or in this case it was somebody to start the movement. Over the years, as the company or the industry grew, it was unavoidable that the organisation opened to be flexible for environmental influences. The transformational theory says that the motivational skills of leaders shall enable their staff to grow, which might cause in the wish of self-fulfilling, freedom and flexibility. In this field of research, it will be the motivational skills of people, companies or organisations to enable societies to grow.

\section{Great Man Theory}

Born and founded in the $19^{\text {th }}$ Century, the "Great Man Theory" explains leaders as Great Men, as charismatic heroes, as people that can change history. "Heroes certainly have their uses. They capture imaginations, unveil possibilities, and rally sympathies. They inspire." (Wynn, 1984, p. 145). Following this statement, the presence of a great man alone is enough to motivate other people. Applying on a modern business environment, a great man can be a charismatic founder of a company, who is able to catch people, or an active and sound sales director who is the one to attract his or her sales staff.

James (1881, p. 89) says that "the plain truth is that the 'philosophy' of evolution is a metaphysic creed, and nothing else", meaning that the "great man" influences by things that are not tangible in common sense and he continuous further that with "It is a mood of contemplation, an emotional attitude, rather than a system of thought". Great Man or Heroes are "larger-than-life" (Wynn, 1984, p. 145), which again expresses their ability to influence metaphysic belief.

\section{Contingency Theory}

As per the word "continency", this theory sees environmental influencing factors as main drivers for decision making and leadership. There is no best-practice in general, but there might be best-practices for cases or circumstances. 
Morgan (2006, p. 38) sees an organisation as an open organism, which must interact and achieve an appropriate relation with that environment, meaning that the organisation must be flexible to adopt to any potential changes in the environment. This approach can be somehow seen as controversial to the Great Man Theory, as this theory sees the leader as the reason for success or failure, and not the influencing factors from outside.

Fiedler (1986, p. 533) goes even further with his cognitive resource theory saying that even within an organisation, leadership adaptions daily are unavoidable. Staff behaviour in terms of stress level, group and leader support may vary from one situation to the other, resulting in the need for leadership style adjustments. Fiedler's Contingency Model of Leadership Effectiveness (1964) "attempts to spell out the specific conditions under which certain leadership attitudes result in effective Performance", showing that already more than 50 years back this situational approach to leadership was of high importance.

The Contingency Theory therefore cannot be a universal valid approach to general leadership management, as it implies the necessity of knowing other theories to be used in specific depending circumstances. The essence of this leadership theory might be - setting the right steps in the right moment.

\section{Transformational Theory}

Transformational leadership can be applied when trying to increase participation and motivation in teams and to identify a potential need for change. In contrast to the transactional leadership, where rewards are the main incentives for effort, the transformational leader tries to motivate typically by charisma, inspiration, intellectual stimulation and individualised consideration (Bass' 1990, p. 22), resulting in an increased performance of the staff. This model could be very modern, as in a common business environment in the recent years motivation and enabling the staff to grow is key to success. However, this theory also can be linked to the great man theory, where an individual came up with an idea and other followed. Means that the difference between the two theories per se might be small, in a real business environment the difference is quite big as the transformational approach can be applied throughout all hierarchical steps of an organisation, while the great man approach is limited to the idea that that people just become leaders and not taken influencing factors into consideration.

The four I's often refer to a kind of best practice for transformational leadership, named Individualised consideration, Intellectual stimulation, Inspirational motivation, and Idealised influence (Avolio, 1991, p. 13). Summed up the transformational leader is not leading by promising 
incentives or threatening, but on a very emotional and individual level where it becomes harder for the people to neglect the positive emotions and actions the leader is offering.

\section{Contextual Transition to Change Management}

"The globalization of markets and the rapid diffusion of information and communications technologies have transformed the economies of the developed countries of the world. (Dess, 2000, p. 1)", which was written already in the beginning of the recent century. Nowadays, the speed of information flow, worldwide transparency and unlimited access to all written sources is even higher and the effects of modernisation might be even more severe, considering leadership and style of leadership. Speeches are present and available in the media and it is easy to get information, but also to seed information.

The above have shown that Leadership Theories can excellently explain the theoretical background which are underlying the leader's decision. It is also obvious, that decisions taken are worth nothing without the correct execution. Especially in critical times, where companies or whole industries might struggle or even fail, this becomes an even higher priority and it is up to the leaders to guide the way throughout the potential crisis. Another quite common expression for overcoming such situations is "Change Management".

\section{Change Management Theory}

When Leadership is the way how to direct a company respectively the people, Change Management is the process how to detect and implement necessary changes. Such changes might not be obvious, which makes it even more difficult to identify the unavoidable steps in order to move forward or to survive. Companies often face challenges from outside, which they are not able to handle with the current structure or setup. This can be financial reasons, new competitors, new technologies, bankruptcy from sub-suppliers and so further. Continuing doing business as usual might not have negative short-term effect, but it will cause in problems on the longer run. The main question for companies in this context at the beginning is, how to recognise the need for change?

There can be many reasons for change - environmental impacts, a new competitor is arising on the market, the technology produced is not state of the art any longer, the founder of the company is retiring, and a new generation is taking over. This means it can be external indicators for change, or also internal indicators like additional benefits for the company or individuals. "Another major factor that motivates change 
is the perception that benefits (as opposed to losses) can be accessed through implementation" (Rousseau, 1990, p. 517). which describes the logic behind the need for change for individuals quite well. As change management shall support and help people or organisations for initiating the change, all different aspects why change shall be implemented must be taken under consideration.

According to John Kotter's 8-Step Process for Leading Change, adapted and modernised by the author in 2012, the following steps are necessary in order to make the change (Kotter 2012, p. 23)

- Establishing a Sense of Urgency - people must realise that something must be done

- Creating the Guiding Coalition - a powerful team is necessary lead the change

- Developing a vision and strategy - vision and strategy support the purpose of making people understand

- Communicating the change vision - before people can understand the purpose, they must know what it is all about

- Empowering broad-based action - a change results in something new - also the process how to get there can be somehow new and untraditional

- Generate Short-Term Wins - a win increases the motivation which will further motivate others

- Consolidating gains and producing more change -motivate and develop the change culture

- Anchoring new approaches in the culture - encourage people to lead changes, to approach others

Kotter's 8-Step process is a quite universal and still up to date method how to start and execute the change in a company or other organisations. Basically, it can be applied to all cases where human interactions happen. Leading the change according to Kotter is one step in how to finally succeed with the intended change. However, there is also the need check the steps and decisions done. W. Edwards Deming (2000, p. 23) not only describes his model of change in his "Principles for Transformation", which is a 14 steps model comparable to the 8-Step process from Kotter, he also invented the so called Plan-Do-Check-Act Cycle, also called Deming Cycle, which represents a management tool to continuously improve the change decisions. Depending on environmental influencing factors, some changes may be preferable over others.

\section{Contextual Transition to Circular Economy}

Leadership and Change Management are the focus areas that can influence people in companies, groups in regions or populations in societies. Depending on how the leader is trying to execute the change, 
people might follow with passion or they don't. In some cases, the leader must make the people follow, it is unavoidable because of a bigger goal that is not only influencing our every day's business life, but also the whole planet and future generations. Consequently, it should be a good and charismatic leader that is enabling the change - it should be a strong organisation that makes the people follow, and the key message must be understood.

\section{Sector and Company Analysis}

Environmental Economy already has its beginning in the 1960's with the work of Kenneth Boulding (1966) in which he tried to show the importance of a sustainable attitude towards our planet and its resources. First officially mentioned in the 1990's by David Pearce (Pearce, 1989 , p. 1), the expression "Circular Economy" is one the biggest and most up-to date words in the whole plastic industry. Every company that is somehow engaged in the Plastic industry is nowadays putting a high focus on sustainability, recyclable products and corporate social responsibility. People and companies are aware that something must be done in order to prevent from even higher plastic waste pollution, same importance has the cleaning of the already existing pollution. This awareness is great and necessary for our planet; however, this awareness is something new and depending on industry, it came up only since a few years. From industrial ecological point of view, the implication exists that a circular economy, consequently, shall be valuable to society and to the economy in general.

Circular economy will reduce the pollution of the planet by keeping the waste and side products in the product life cycle, by recycling, reusing and redesigning. This means that the loss of ones produced material will be minimised, in best case eliminated and products will be put back in the loop even after their initial life cycle. In this context one can also name the first law of thermodynamics, where it says, "that total energy and matter remains constant in a closed system" (Andersen, 2006, p. 2). In the modern circular economy this means avoiding producing new virgin materials and using end of life cycle products as the raw material.

\section{Associations Teams / Cooperation}

Many associations on company level, on regional levels, but also on the European level exist in the nowadays plastic industry. Companies are getting together to boost their ecological approach, to show their social responsibility and to initiate real change. One of the biggest organisations on the European Level is "Plastics Europe", where most European 
companies in the Plastic industry are involved. Companies in the Plastic Industry thereby means Virgin Plastic producers, plastic converters, plastic recyclers and machine manufacturers for the plastic industry.

Recycling today is a necessity and companies realise that. However, for them it is not only a necessity, it is also a huge business. Today, $95 \%$ of plastic packaging material value or an equivalent of USD 80-120 billion annually is lost to the economy after a short first use (Ellen MacArthur Foundation, 2016, p. 26). With efficient waste collecting and recycling initiatives, this lost money can be collected and put back into the material loop, increasing Product Life Cycles, sustainability and avoiding littering.

The European Commission aims at transforming Europe into a more circular and resource efficient economy. Although Europe, compared to the rest the world population is rather small, it is worldwide considered as technology leader in the Plastic Machine Manufacturing Industry and it is technology that will make the change, and which will, if ever, clean the planet from the plastic waste pollution. Of course, education and teaching people not to throw plastic waste somewhere, but collect it recycling friendly, would be the optimum case, but unfortunately it is a romantic and utopian idea to rely on people only on such an important topic.

The "Plastic 2030" voluntary commitment focuses on preventing leakage of plastics into the environment, on improving resource efficiency and the circularity of plastic packaging applications, aiming to make circularity and resource efficiency a reality (Figure 1).

\section{Overarching Goals}

-Prevent leakage of plastics into the environment

-Improve Resource Efficiency

-Improve Circularity of Plastic Packaging

\section{Targets}

-By increasing engagement inside and outside the plastic industry

-By accelerating innovation in the full life cycle of products

- By reaching in 2040 100\% reuse, recycling and/or recovery of all plastic packaging in the whole EU. In 2030 , target is $60 \%$ reuse and recycling of all plastic packaging



Figure 1. Goals and Targets of the "Plastic 2030" Voluntary Commitment Source: "Plastic 2030" Voluntary Commitment 
Preventing leakage for producing companies and for the recycling machine industry means increasing the ratio of materials put back into the loop respectively not leaving the loop. Once having left the loop, an efficient collecting of the waste materials is required in order to achieve the recycling rates required. One can separate two different streams when it comes to Plastic waste:

Post-Industrial waste - plastic waste that occurs during the production of plastic products. In every production process, there are some side products or waste that is cut off. This post-industrial waste typically does not really leave the loop as recycling companies are eager to get this waste material as a valuable material source.

Post-Consumer Recycling - as per the keyword itself, a consumer already used the waste that shall be recycled. Due to cross contamination with other polymers, different contamination and other influencing factors, post-consumer recycling will be the bigger challenge for making Circular Economy happen. Many different technologies are available on the market, in any case efficient Post-Consumer Recycling requires quite high investments and running costs in order to create a product that can be used again in the material loop.

\section{Jobs - Over 1,5 Million People}

-The Plastic Industry gives direct employment to more than 1,5 Million people in the European Union

Companies - Close to 60,000 companies

-An industry in which close to 60,000 companies operate, most of them SME's

\section{Turnover - More than 350 billion $€$}

-The European Plastic Industry had a Turnover of 355 billion $€$ in 2017

\section{Trade Balance - 17 billion $€$}

-The European Plastic Industry had a trade balance of more than 17 billion $€$ in 2017

Public Finances - More than 30 billion $€$

-The European Plastic Industry contributed to 32,5 billion $€$ to public finances and welfare in 2017

Multiplier Effect $-\times 2.4$ in GDP and almost $\times 3$ in jobs

-The European Plastic Industry has a multiplier effect in x2.4 in GDP and almost x3 in jobs

\section{Industrial Value Added - \#7 in Europe}

-The European Plastic Industry ranks \#7 in Europe in industrial value added contribution. At the same level as the pharmaceutical industry and close to the chemical industry.

\section{Recycling - over 8,4 million tonnes}

-In 2016, over 8,4 million tonnes of plastic waste were collected in order to be recycled inside and outside the EU

Figure 2. Key Figures of the European Plastic Industry

Source: Plastics Europe Association - Plastics the Fact, pp. 12-13 
Research and Development on alternative products and or alternative environmentally friendly polymers are ongoing in the industry, as well as sector specific commitments to develop guidelines, innovations and standardisation. Product Life Cycle extensions by improved properties, Restrictions for recycling unfriendly plastic products combinations and Quality Standards for Collecting are just some of the initiatives pushed forward by the European plastics associations.

Figure 2 shows the strength and the size of the plastic industry in Europe. It includes plastics raw materials producers, plastics converters, plastics recyclers and plastics machinery manufacturers in the EU28 Member States.

Plastic products are inevitable in our daily life. Plastic is used as packaging materials, plastic fibres are used for clothes, in automotive and building industry Plastic is an inherent material. Figure 3 shows the distribution of Plastic products are converted by industries and applications.


Figure 3. Plastic converter demand main market sectors

Source: Plastics Europe Association - Plastics the Fact, p. 24

Many different industries require the use of plastic and an alternative will be difficult to find. The huge variety of different polymer types enables the converter to use the excellent properties of plastic in many different applications. Another advantage is that plastic is still a quite cheap raw material and it is recycling friendly when in the right combination. The European Union is setting steps in order to increase the ratio of recycling friendly polymer combinations, which mainly means using mono-materials only. For example, a mono-material plastic packaging is 
packaging film that consists of a single polymer only. This structure makes is quite recycling friendly and reusable for a next product life cycle, while a multilayer structure, respectively multipolymer structure results in difficulties when recycling and a limited amount of final applications after recycling for such products.

\section{Current Status of Recycling Initiatives}

Plastic Recycling nowadays is a huge topic worldwide, but especially in the European Union. Subsidies are paid for companies starting recycling plants, initiatives to boost the Circular Economy are coming up and many companies already formed associations to use their individual competencies together with others in order to create synergy effects for their recycling purposes. All those initiatives, in addition with the increased people's awareness of waste separating and collecting is resulting in an $80 \%$ higher recycling rate compared to 2006, visualised in Figure 4. Landfill collection thereby results in a minus of $43 \%$, Energy Recovery in a plus of $61 \%$ and the Recycling rates in a plus of 79\% from 2006 to 2016.

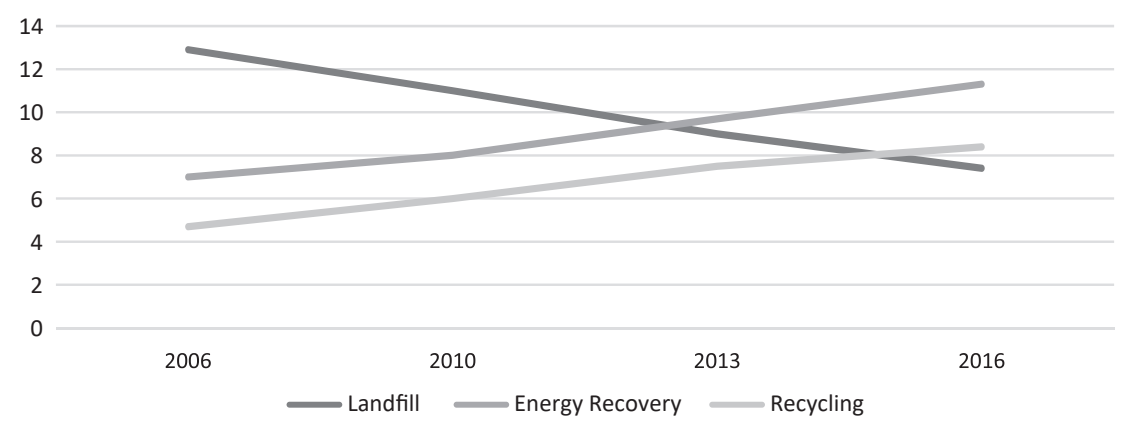

Figure 4. Evolution of plastic waste treatment 2006-2016 in million tonnes Source: Plastics Europe Association - Plastics the Fact, p. 32

This efforts from all EU members results in high national recycling rates all over the states and leads to the fact that the EU plastic packaging recycling rate is $18 \%$ higher than what was asked by the EU Packaging Waste Directive (Figure 5). The new plastic packaging recycling target for 2025 is set to $50 \%$, where some countries are already very close now respectively some of them already reach this target or settle above. As a limitation of this numbers it is obvious that only the plastic packaging is concerned, not the other applications where plastic is used. However, plastic packaging 
is one of the main drivers for post-consumer waste, where main focus in Circular Economy is set on anyhow.

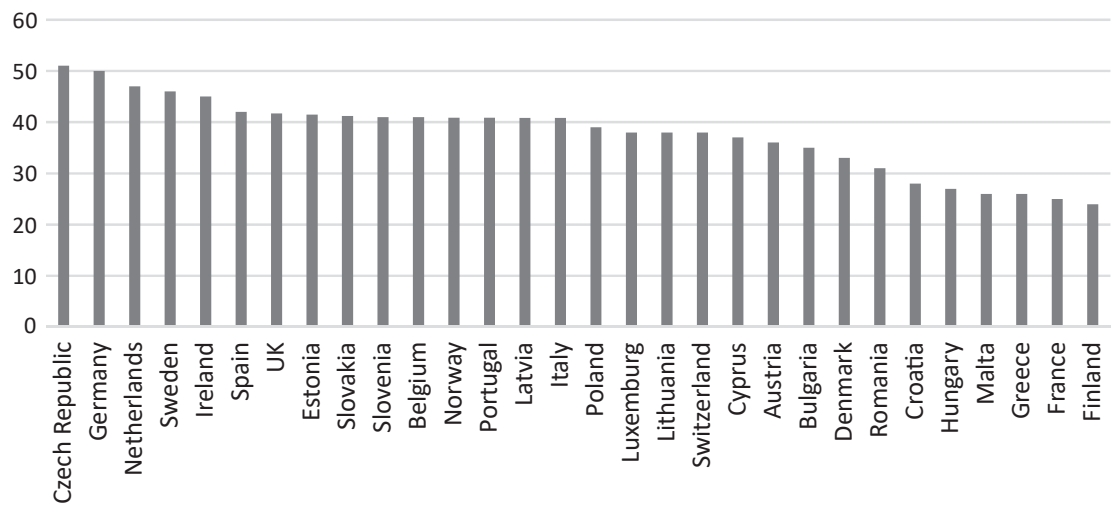

Figure 5. Plastic Packaging Recycling rate per country in 2016 in \% Source: Plastics Europe Association - Plastics the Fact, p. 39

Outlook and Strategies to Transform the Plastic Packaging Market into Circular Economy from Ellen MacArthur Foundation in 2016 (The new Plastics Economy, 2016, p. 31):

- Create an Effective After Use Plastics Economy

- Drastically Reduce the Leakage of Plastic

- Decouple Plastics from Fossil Feedstocks

In 2017, the Ellen Mac Arthur Foundation (The new Plastics Economy 2017, pp. 52-55) adds further targets for the near future of plastic recycling:

Fundamental Redesign and Innovation - Necessity of avoiding multilayer structures is clear. Without this redesign and innovation, approximately $30 \%$ of plastic packaging will never be reused of recycled. Here the virgin manufacturers, but mainly the producers of the plastic packaging are taken into responsibility, as they are the only ones that can initiate the change in this field.

Reuse - for at least $20 \%$ of plastic packaging, reuse provides an economically attractive opportunity. Reusing of course won't be possible for packaging materials that are subject to applications where hygiene and food safety is of importance. However, there are many other packaging types than can easily be used again in their existing shape.

System Approach - with concerned efforts to redesign packaging and the systems for managing after the use of it, recycling would be economically attractive for the remaining $50 \%$ of plastic packaging. 


\section{Analysis and Interpretation}

It is obvious from the data given, that there are many initiatives already existing in the European Plastic Industry. Recycling rates grew dramatically which is decreasing the problem of landfilling. All countries in Europe are following the European directives. It may be because of international pressure or the own awareness of the necessity. Basically, it does not really matter why the rates are high and fulfilled, if the rates are high and continuously growing.

International pressure definitely will be a reason why countries are following the recycling goals to enable the Circular Economy. Nobody wants to step behind others on such an important topic, and the topic still is - saving the planet, or at least contributing to saving the planet, as plastic pollution is not the only source of worldwide pollution. Pressure from outside means receiving directives, receiving orders, receiving targets. The giver of such orders should be a great man, but flexible to influences from outside with the ability to motivate people to follow and grow. This would be somebody who is able to embody the combination of the great man theory, the contingency theory and the transformational theory and transfers the ideas behind into real actions.

Kotter's 8-Step Process for Leading Change can be perfectly set in context with the growing Circular Economy (Figure 6).

Establishing a Sense of Urgency - people, organisations and countries must realize that something must be done, otherwise the Plastic Pollution worldwide will grow significantly. Production of Plastic products will grow, but sources of Plastic must change as well and the adaption to a Circular Economy is just the first Step to change the wheel.

Creating the Guiding Coalition - a powerful team is necessary lead the change. In this context, where basically the world and all its inhabitants are the "company", a team could be an association of big international companies or even countries that join to a common goal, which is bigger than just economic success.

Developing a vision and strategy - vision and strategy support the purpose of making people understand. Many "green" initiatives try to clean the planet from Plastic pollution. It may be the, in social media well known, cleaning of India's beaches, the recycling ships or fabric manufacturers using $100 \%$ recycled sea plastic. The ideas are wide and big, and luckily, due to nowadays technology, most of the ideas are realisable. However, the vision and strategy just must be strong enough to catch the people, as this is the only unstable variable.

Communicating the change vision - before people can understand the purpose, they must know what it is all about. The initiatives 
communicate quite clear as well as the trend where all the initiatives are heading towards - usage of recycled plastic instead of virgin plastic:

Empowering broad-based action - a change results in something new also the process how to get there can be somehow new and untraditional. In Far Eastern countries, people get "points" for being a good citizen who throws the plastic waste into the correct box, in Pakistan people get paid for each PET bottle that they collect, international celebrities force the Circular Economy and create awareness on the problem of plastic pollution. This might be new to the people, as usually companies or local communities solely took care of waste collection.

Generate Short-Term Wins - a win increases the motivation which will further motivate others. In nowadays media, especially in dedicated Plastic magazines, one can read an innovation in this sector every day. Many of those innovations are really promising and can make a change, most of them are related to new technologies. All those steps and innovations can be seen as a Short-Term win, but also social projects like the already mentioned cleaning of some Indian beaches.

Consolidating gains and producing more change - motivate and develop the change culture. Once a change is done and first wins are succeeded, the goal must be to initiate more change, more motivation to others and an increasing awareness. The example of the Indian beach cleaning initiative can be a great example for other areas on the planet.

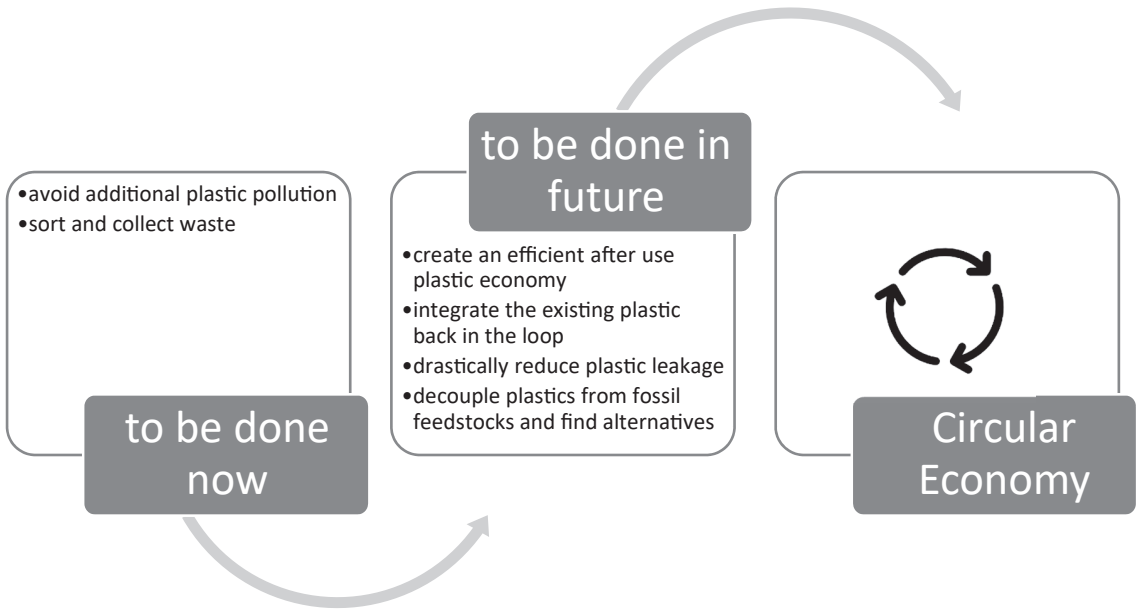

Figure 6. The Circular Economy for Plastics

Source: Authors own work 
Anchoring new approaches in the culture - encourage people to lead changes, to approach others. Celebrities, children demonstrating on Fridays against the Climate Change, and many other examples demonstrate that this is already happening when looking at avoiding plastic waste and pushing Circular Economy.

It was the pure production of plastic products only in the past the industry nowadays tries to integrate sustainability and circular economy in the daily business life? Strong leadership actions and an efficient change management will be now necessary in order to make the useful initiatives come true, increase the awareness of the people that they are the ones to start, and finally, realise a Circular Economy to minimise the planet's exploitation.

\section{REFERENCES}

Andersen, M. S. (2006). An introductory note on the environmental economics of the circular economy. Integrated Research System for Sustainability Science.

Avolio, B. J., Waldman, D. A., Yammarino, F. J. (1991). Leading in the 1990s: The Four I's of Transformational Leadership. Journal of European Industrial Training, 15(4).

Bass, B. M. (1990). From Transactional to Transformational Leadership: Learning to share the Vision. Organizational Dynamics, 18(3), pp. 19-31.

Boulding, K. E. (1966). The Economics of the Coming Spaceship Earth. Environmental Quality in a Growing Economy, Resources for the Future, Johns Hopkins University Press, pp. 3-14.

Deming, W. E. (2000). Out of the Crisis. The MIT Press.

Dess, G. G., Picken, J. C. (2000). Changing roles: Leadership in the 21 st century. Organizational Dynamics, 29(4), 18-33.

Ellen MacArthur Foundation - The New Plastics Economy: rethinking the future of plastics and catalyzing action (2016).

Ellen MacArthur Foundation - The New Plastics Economy: rethinking the future of plastics and catalyzing action (2017).

Fiedler, F. E. (1986). The contribution of cognitive resources to leadership performance. Journal of Applied Social Psychology, 16(6), pp. 532-548.

Fiedler, F. E. (1964). A theory of leadership effectiveness. Advances in experimental social psychology. New York: Academic Press.

James, W. (1881). On great men and great thoughts versus environment. Journal of Speculative Philosophy, 15(1), pp. 88-91.

Kotter, J. P. (2012). Leading Change. Boston: Harvard Business School Press.

Morgan, G. (2006). Images of Organizations. Schulich School of Business, Sage Publications.

Pearce, D. W., Turner, R. K. (1989). Economics of Natural Resources and the Environment. Johns Hopkins University. 
Plastics Europe Association (2018). Plastics the Fact. An analysis of European plastics production, demand and waste data.

Rousseau, D. M., Tijoriwala, S. A. (1999). What's a Good Reason to Change? Motivated Reasoning and Social Accounts in Promoting Organizational Change. Carnegie Mellon University. Journal of Applied Psychology, 84(4), pp. 514-528.

Wynn, G. (1984). On Heroes, Hero-Worship, and the Heroic in Environmental History. Department of Geography University of British Columbia, V6T 1 Z2. 